\title{
Management of Pregnancy Complicated by Diabetes
}

\author{
J. M. G. HARLEY,* M.D., M.R.C.O.G. ; D. A. D. MONTGOMERY, † M.B.E., M.D., F.R.C.P.
}

Brit. med. F., 1965, 1, 14-18

In 1956 Stevenson published the results of 119 diabetic pregnancies treated in the Royal Maternity Hospital, Belfast, during the 16-year period 1940 to 1955 . As a result of his findings he concluded that some improvement in the foetal mortality should be possible and recommended (1) that there should be the closest co-operation between obstetrician, physician, and paediatrician; (2) strict antenatal care from the beginning of pregnancy; (3) admission to hospital at the twenty-eighth week, or earlier if stabilization is unsatisfactory ; (4) premature delivery at 35 weeks, or earlier if indicated ; (5) delivery by caesarean section in all primigravidae and all but a very few multigravidae; and (6) skilled nursing of the neonate in a modern nursery unit.

For the past eight years the management of diabetic pregnancies in the Royal Maternity Hospital, Belfast, has been influenced to some extent by these recommendations. Consequently it was decided to carry out a further review to see if there had been any improvement in the foetal mortality and whether or not any alterations were necessary in our present management.

\section{Series Reviewed}

Diagnosis.-The correctness of the diagnosis of diabetes was confirmed in all patients under review. The majority were established diabetics attending the diabetes clinic of the Royal Victoria Hospital and receiving regular treatment with insulin. A few were referred from other clinics. The diagnosis was suspected for the first time in pregnancy in five patients. It was confirmed by abnormal oral glucose-tolerance tests after delivery. Patients who during pregnancy had an abnormal oral glucose-tolerance test which reverted to normal after delivery were excluded from this series.

Incidence.-In the eight years from January 1956 to December 1963 a total of 80 diabetic patients who had 113 pregnancies were treated in the Royal Maternity Hospital, Belfast. Fifty-five had one pregnancy, 17 had two pregnancies, and eight had three pregnancies. During the same period 17,074 patients were delivered in the hospital. This gives an incidence for diabetic patients of $0.66 \%$, which is slightly higher than that of the previous five years, and nearly twice that during the 11-year period 1940 to 1950 (Table I). This increase

TABLE I.-Incidence of Diabetic Pregnancies, Royal Maternity Hospital,

\begin{tabular}{|c|c|c|c|c|}
\hline$\cdot$ & & $\begin{array}{c}\text { Total } \\
\text { Patients }\end{array}$ & $\begin{array}{c}\text { Diabetic } \\
\text { Pregnancies }\end{array}$ & $\begin{array}{l}\text { Percentage } \\
\text { Incidence }\end{array}$ \\
\hline $\begin{array}{l}1940-50 \ldots \\
1951-55 \ldots \\
1956-63 \ldots\end{array}$ & $\begin{array}{ll}. . & . . \\
\because & \end{array}$ & $\begin{array}{l}19,361 \\
10,363 \\
17,074\end{array}$ & $\begin{array}{r}67 \\
52 \\
113\end{array}$ & $\begin{array}{l}0.34 \\
0.5 \\
0.66\end{array}$ \\
\hline
\end{tabular}

in incidence for diabetic patients is similar to that found by other writers. The number of diabetic patients treated over the last eight years was only six fewer than that dealt with in the previous 16 years. This finding is not altogether unexpected in view of the fact that in the diabetes clinic of the Royal

* Lecturer in Obstetrics and Gynaecology, the Queen's University of Belfast; Consultant Obstetrician and Gynaecologist, Royal Maternity and Royal Victoria Hospitals, Belfast.

† Physician-in-Charge, the Sir George E. Clark Metabolic Clinic, Royal Victoria Hospital, Belfast.
Vintian
Victoria Hospital, Belfast, which is in the same hospital group as the Royal Maternity Hospital, the number of new patients seen over the same eight years increased from 115 in 1956 to 594 in 1963.

Age of Onset.-Of the 80 patients in the present series, 32 $(40 \%)$ were under 20 years of age when the diagnosis of diabetes mellitus was made, $46(57.5 \%)$ were 20 years or over, and in the remaining two the age of onset was unknown.

Duration of Diabetes.-The duration of the diabetes was 10 years or less in $61(53.9 \%)$ and over 10 years in $45(39.8 \%)$. In five patients, as already stated, the diagnosis was suspected for the first time during pregnancy and subsequently confirmed after delivery. In the remaining two patients the duration of the diabetes was unknown.

\section{Control of the Diabetes}

Patients were seen at fortnightly intervals or more often where indicated. Postprandial (three-hour) blood glucose levels were estimated from venous-blood samples using the Technicon Autoanalyzer. Mid-morning (11 to 11.30 a.m.) and midevening ( 8.30 to 9 p.m.) results were available before each visit. In addition all brought a record of their urine tests for glucose and acetone, carried out with Clinitest and Acetest tablets, on freshly voided samples (fasting and before the main meals of the day) during the seven days preceding the visit to the clinic.

Control of the diabetes was judged to be good if the average blood glucose level 3 hours after breakfast and the evening meal was $150 \mathrm{mg} . / 100 \mathrm{ml}$. or less and hypoglycaemic reactions were infrequent. Blood glucose values of 151 to $200 \mathrm{mg}$./100 $\mathrm{ml}$. were regarded as fair, while levels above $200 \mathrm{mg} . / 100 \mathrm{ml}$. were unsatisfactory and designated poor. The degree of glycosuria was ignored in the assessment of control because of the disturbing effect of pregnancy on the renal excretion of glucose. When these criteria were adopted for the 101 pregnancies treated with insulin, $69(68.3 \%)$ had good control, 21 (21.2\%) had fair control, and $7(7.1 \%)$ had poor control, and in 4 the control was uncertain (Table II). All eight patients treated by diet

\begin{tabular}{|c|c|c|c|c|c|c|c|c|c|}
\hline \multirow{2}{*}{\multicolumn{5}{|c|}{ Treatment }} & \multirow{2}{*}{ Total } & \multicolumn{4}{|c|}{ Diabetic Control } \\
\hline & & & & & & Good & Fair & Poor & Uncertain \\
\hline $\begin{array}{l}\text { Insulin } \\
\text { Diet only } \\
\text { Chlorpropam } \\
\text { Untreated-en }\end{array}$ & $\begin{array}{l}\cdots \\
\text { nide } \\
\text { mergenc }\end{array}$ & $\begin{array}{l}\ddot{ } \\
\ddot{y} \\
\text { adm }\end{array}$ & $\begin{array}{c}\cdots \\
\ddot{0} \\
\text { issions }\end{array}$ & $\begin{array}{l}\cdots \\
\cdots \\
\cdots\end{array}$ & $\begin{array}{r}101 \\
8 \\
2 \\
2\end{array}$ & $\begin{array}{r}69 \\
8 \\
2 \\
-\end{array}$ & E & $\frac{7}{\overline{2}}$ & $\begin{array}{l}4 \\
- \\
-\end{array}$ \\
\hline Total & $\ldots$ & . & . & . & 113 & 79 & 21 & 9 & 4 \\
\hline
\end{tabular}

only were well controlled and so were the two patients treated with chlorpropamide. Two patients who were admitted as emergencies and were untreated during pregnancy had poor control.

\section{Foetal and Maternal Mortality}

Table III shows the foetal mortality in the present series compared with the two previous series reported by Stevenson (1956). In the 113 diabetic pregnancies treated during 1956-63: 
there were two sets of twins, making the total number of foetuses 115 . The total foetal loss was 19 (16.5\%). In six patients the pregnancy ended as a miscarriage. This leaves 109 viable foetuses, 13 of them dying, a perinatal mortality of $11.9 \%$. These results are compared with those reported by other authors in Table IV.

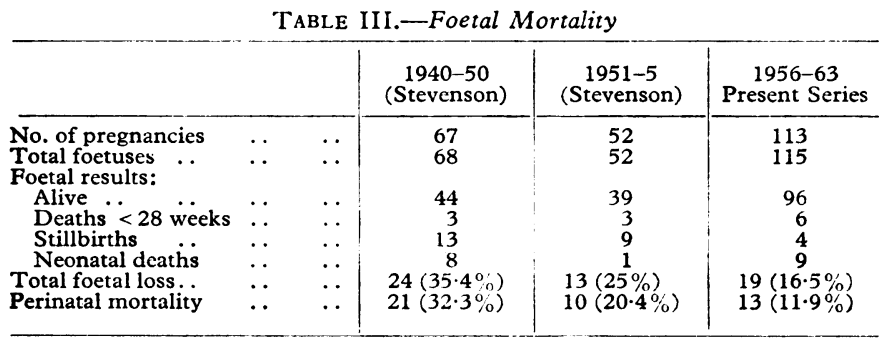

TABLE IV.-Comparison of Foetal Mortality Results (Viable Foetuses)

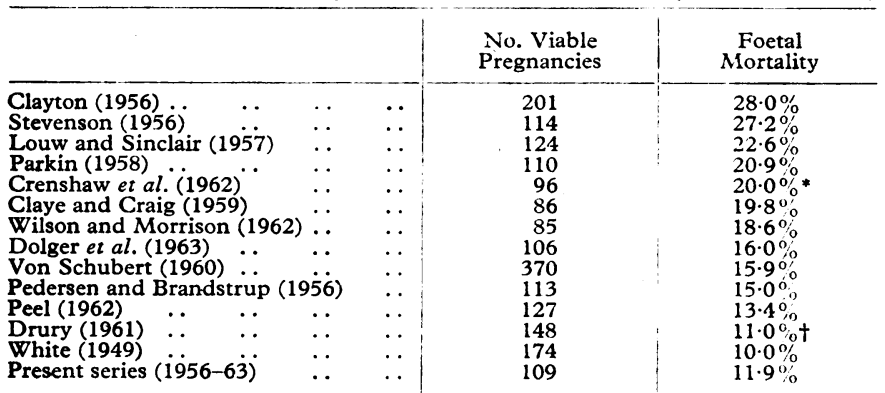

* Excludes 3 intrauterine deaths which occurred before patient was referred to hospital. $t$ Excludes 6 cases of intrauterine death which occurred before patient was
referred to hospital.

One stillbirth occurred in a patient who was an unsuspected diabetic and had received no treatment until her emergency admission at 38 weeks with an intrauterine death. Two of the neonatal deaths were associated with foetal abnormalities-one with multiple abnormalities incompatible with life, and the other with absence of the left kidney. No correction for these deaths is made. One unfortunate patient lost three consecutive pregnancies; her first ended as a miscarriage, and in the two subsequent pregnancies both babies died within an hour of delivery.

There were 33 primigravidae, an incidence of $29.3 \%$. Among these, one pregnancy ended as a miscarriage and five viable babies were lost, a perinatal mortality of $15.1 \%$. In the remaining 80 multigravidae, five pregnancies ended as miscarriages and eight viable babies were lost, a perinatal mortality of $10.5 \%$. These figures are similar to those of Drury (1961), who found a perinatal mortality in primigravidae of $21 \%$ and in multiparae of $9 \%$.

No maternal deaths occurred in the present series.

The relation of the foetal mortality to diabetic control is shown in Table V. The results suggest that the better the control the better the prognosis. In the fair and poor control groups the figures are too small for satisfactory statistical analysis; however, when these two groups are combined and then compared with the good control group, the results showed

TABLE V.-Foetal Mortality Related to Diabetic Control

\begin{tabular}{|c|c|c|c|c|c|}
\hline \multirow{2}{*}{\multicolumn{2}{|c|}{ Foetal Mortality }} & \multicolumn{4}{|c|}{ Diabetic Control } \\
\hline & & Good & Fair & Poor & Uncertain \\
\hline 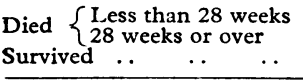 & $\begin{array}{l}\cdots \\
\cdots \\
\end{array}$ & $\begin{array}{l}2 \\
6 \\
71(73) \\
\end{array}$ & $\begin{array}{r}2 \\
4 \\
15\end{array}$ & $\begin{array}{l}1 \\
3 \\
5\end{array}$ & $\begin{array}{l}1 \\
0 \\
3\end{array}$ \\
\hline Total ... & . & $79(81)$ & 21 & 9 & 4 \\
\hline $\begin{array}{l}\text { Perinatal mortality rate } . \\
\text { Total foetal mortality rate }\end{array}$ & $\because$ & $\begin{array}{l}7 \cdot 6 \% \\
9 \cdot 8 \%\end{array}$ & $\begin{array}{l}21 \cdot 0 \% \\
28 \cdot 6 \%\end{array}$ & $\begin{array}{l}37 \cdot 5 \% \\
44 \cdot 4 \%\end{array}$ & $25 \%$ \\
\hline
\end{tabular}

Figures in parentheses include extra babies due to twins. that the perinatal mortality was significantly better in the good control group $\left(\chi^{2}=7.82\right.$; D.F. $\left.=1 ; \mathrm{P}<0.01\right)$.

That these results might have been influenced by any other major factors which affect the perinatal mortality is unlikely because there were no significant differences between the good and fair + poor control groups in age $\left(\chi^{2}=1.43 ;\right.$ D.F. $=1$; $P>0.2)$, parity $\left(\chi^{2}=2.30 ; D . F .=1 ; P>0.1\right)$, maturity at delivery $\left(\chi^{2}=1.42 ;\right.$ D.F. $\left.=2 ; \mathrm{P}>0.3\right)$, method of delivery $\left(\chi^{2}=1.62 ; \mathrm{D} . \mathrm{F} .=1 ; \mathrm{P}>0.2\right)$, and incidence of pre-eclampsia $\left(\chi^{2}=2.07 ;\right.$ D.F $\left.=1 ; \mathrm{P}>0.1\right)$.

\section{Complications}

The complications that occurred are shown in Table VI.

TABLE VI.-Complications
$\begin{array}{rlll}\text { No. } & & & \\ 55(51 \cdot 4 \%) & \text { Hypoglycacmic coma } & \ldots & \text { No. } \\ 40(37 \cdot 3 \%) & \text { Hyperglycaemic coma } & \ldots & 2 \\ 8(7 \cdot 0 \%) & \text { Monilia vaginitis } & \ldots & 3 \\ 5(4.7 \%) & \text { Abscess in groin } & \ldots & 1 \\ 3 & \text { Ruptured uterus } & \ldots & 1 \\ 3 & \text { Cerebral vascular accident } & 1\end{array}$

Polyhydramnios.-This complication was recorded in the notes of $55(51.4 \%)$ patients, This is higher than the $31 \%$ reported by Stevenson (1956). A possible explanation is that in the past eight years the presence of polyhydramnios was recorded more accurately in the charts of patients whose pregnancies were complicated by diabetes.

Pre-eclampsia.-The incidence of this complication in diabetic pregnancies varies considerably in the different published series, ranging from $13 \%$ (Peel, 1955) to $47.7 \%$ (Parkin, 1958). This wide variation may be explained by the different criteria used by the various authors for the diagnosis of preeclampsia. In the present series the criterion adopted was any patient exhibiting two or more of the following signs-hypertension, oedema, proteinuria. Using this criterion there were 40 pregnancies with this complication. If the six pregnancies that ended as miscarriages are excluded, the incidence of preeclampsia is $37.3 \%$. This figure is much higher than the incidence of $16 \%$ found by Stevenson (1956). The difference is difficult to explain, as the criterion used for the diagnosis of pre-eclampsia is the same in the two series. In the 40 pregnancies with pre-eclampsia there were two stillbirths and five neonatal deaths, a perinatal mortality of $17.5 \%$. The perinatal mortality in 67 pregnancies not complicated by pre-eclampsia was $8.7 \%$. These results show the serious effect that pre-eclampsia has on the perinatal mortality in diabetic pregnancies.

Pulmonary Tuberculosis.- This was present as a complication in eight $(7 \%)$ of the patients. In five patients the disease was described as healed following hospital treatment, and the remaining three still had active lesions.

Foetal Abnormalities.-Of the viable babies, five (4.7\%) were abnormal. There were two cases of congenital heart disease and both babies survived. Two were hydrocephalics, one of whom had other abnormalities incompatible with life and the other was still alive at the time of writing. In the remaining case the left kidney was absent and the baby died within 48 hours of delivery. The incidence of foetal abnormalities in this series is similar to those of Stevenson (1956) (5.8\%) and Drury (1961) $(8.2 \%)$, but is much lower than that found by Claye and Craig (1959) (13.3\%) and White (1959) (13.1\%).

Anaemia.-The low incidence of anaemia can probably be attributed to the strict antenatal supervision of these patients.

Ruptured Uterus.-The one case of ruptured uterus occurred in a gravida- 6 at 38 weeks' maturity who was not booked for hospital confinement and was admitted as an emergency in labour. The rupture occurred during labour, and was presumably due to disproportion as the baby weighed $9 \mathrm{lb}$. $11 \mathrm{oz}$. (4.4 kg.). The baby survived after caesarean section. 
The other complications given in Table VI are not altogether unexpected when one is dealing with diabetic pregnancies.

\section{Management}

The results of this review show that over the past eight years the perinatal mortality in diabetic pregnancies managed in the Royal Maternity Hospital, Belfast, has been reduced to $11.9 \%$, which is nearly half that of the previous five years. This reduction is encouraging, and those factors in the management of diabetic pregnancies which are thought to be mainly responsible are now considered under the following main headings-(1) antenatal care, (2) maturity at delivery, (3) method of delivery. At the same time we discuss certain alterations in our present management which we have adopted in an attempt to improve the perinatal mortality rate still further.

\section{Antenatal Care}

Control of the Maternal Diabetes.-There is no doubt that control of the maternal diabetes is one of the most important factors which affect the incidence of the various complications and the perinatal mortality in diabetic pregnancies. Table VII, which compares the management in the present series with that in the series reported by Stevenson (1956), shows that there has been an improvement in those aspects of antenatal care which are so necessary for achieving adequate control of the maternal diabetes-particularly the increase in the number of patients booked for hospital confinement, the greater number attending early in pregnancy, and the more frequent antenatal visits. Much of the credit for the improved perinatal mortality is likely to be due to stricter antenatal supervision and more adequate control of the maternal diabetes, and the management of diabetic pregnancies should therefore be directed primarily towards these goals.

TABLE VII.-Comparison of Management 1940-55 and 1956-63

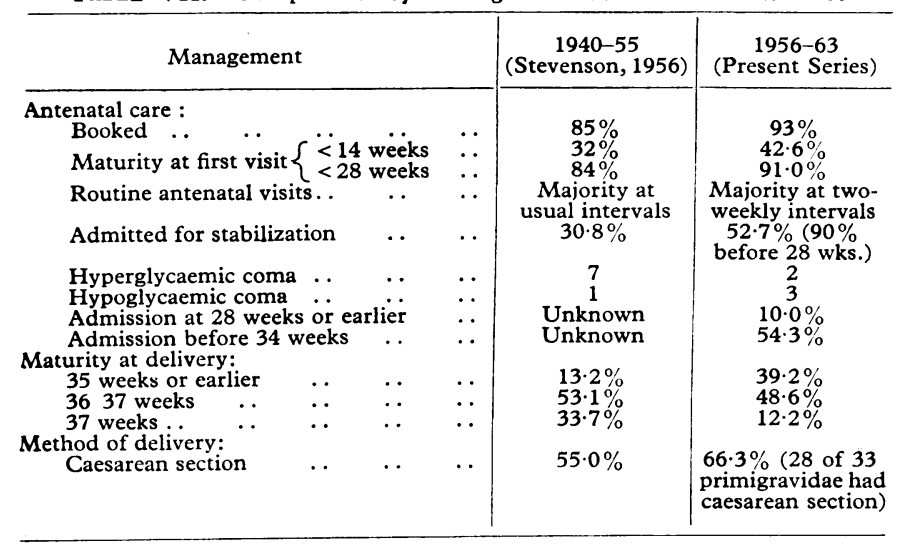

Diabetic patients should, where possible, be referred to an antenatal clinic of a maternity hospital that has the experience and necessary facilities for treating them. Preferably, where the numbers warrant it, these patients should be seen at a special clinic which is attended by both the physician and the obstetrician who will be responsible for their care throughout pregnancy and delivery: only in this way can each appreciate the other's problems. Such a clinic was started some months ago in the Royal Maternity Hospital, Belfast, and has proved very popular with the patients as it combines two of their regular hospital visits. Antenatal visits combined with supervision of the diabetes must be at fortnightly intervals or more often if necessary. Regular blood-glucose estimations should be made, and if at any time stabilization is unsatisfactory immediate admission to hospital must be arranged. In our experience good control of diabetes in pregnancy is difficult to achieve with a single morning injection of a medium- or long-acting insulin whether given alone or in combination with a dose of soluble insulin. We have virtually abandoned this practice except in the mildest cases, and prefer the routine use of either soluble insulin twice daily or a medium-acting insulin such as isophane twice daily or given in the morning alone with an evening (6 p.m.) supplement of soluble insulin. Increasing experience of this method confirms its value in providing better and smoother control with a smaller total daily dose of insulin than when stabilization is attempted with a single daily injection of insulin given in the morning.

Prevention of Miscarriages.-There were six patients in the series whose pregnancies ended as miscarriages. This gives an incidence of $5.3 \%$, which is much the same as Stevenson's $(3.3 \%)$ but lower than that found by other authors (Barns and Morgans, 1948, 10.9\% ; Drury, 1961, 13.1\% ; Crenshaw et al., 1962, $13.0 \%)$. The seriousness of this complication can be appreciated by the fact that miscarriages were responsible for approximately one-third of the total foetal loss in the present series. It is difficult, on the numbers available, to incriminate any particular aetiological factor and even diabetes itself. However, poor control may be responsible for some of the miscarriages, and it is to be hoped that by seeing these patients earlier in pregnancy and improving their diabetic management some reduction in the numbers will result. In patients who have a history of a previous miscarriage the possibility of an oestrogen-progesterone imbalance in early pregnancy should also be investigated by regular vaginal cytology, and, if present, treated.

Prevention of Infection.-The increased risk of infection in patients with diabetes must always be remembered, especially as any infection may rapidly interfere with adequate control of the patient's diabetes. In view of this, the presence of infection is usually an indication for admission to hospital, particularly infections of the respiratory or genito-urinary systems. Monilial vaginitis, commonly found in diabetes, is even more frequent in those who are pregnant, and requires early and adequate treatment.

Radiography.-The presence of pulmonary tuberculosis in these patients must be excluded. Routine $x$-ray examination of the chest should be carried out at the first visit, unless the patient has recently been screened by a mass radiography unit or is already under the care of a chest physician. An $x$-ray examition of the abdomen for maturity is advisable because clinical assessment of maturity may be very misleading in diabetic pregnancies owing to the frequent occurrence of polyhydramnios and big babies. As premature delivery of the foetus is always carried out an accurate assessment of maturity is essential. The presence of any skeletal abnormalities of the foetus should also be looked for.

Admission to Hospital Prior to Delivery.-The recommendation by Stevenson (1956) that admission to hospital before delivery should be at 28 weeks' gestation or earlier was not adopted unless there was some definite indication; in fact, excluding temporary admissions for stabilization, only $10 \%$ of the patients in this series were admitted at 28 weeks or earlier (Table VII). Admission as early as this does not seem to be necessary unless there is some complication, for our experience over the past eight years suggests that admission to hospital approximately four weeks before the proposed date of deliverythat is, admission around the thirty-second week of gestation -is quite satisfactory. In the present series $54.3 \%$ of the patients were admitted before 34 weeks. The perinatal mortality for this group was $9.8 \%$ and for those admitted after 34 weeks $14.6 \%$. The importance of admitting diabetic patients at the thirty-second week needs emphasizing, for it ensures that if any patient should develop pre-eclampsia the necessary steps can be taken immediately to control what is undoubtedly a complication associated with a greater foetal mortality. Similarly, the maternal diabetes can be kept strictly under control during the weeks leading to delivery and at a time when the risks of intrauterine death are increasing. 


\section{Maturity at Delivery}

Management of the pregnant diabetics over the past eight years was greatly influenced by Stevenson's recommendation that premature delivery should be carried out at 35 weeks or earlier. It can be seen from Table VII that the number of deliveries at 35 weeks or earlier increased from $13.2 \%$ in the previous series to $39.2 \%$ in the present series. On reflection we now disagree completely with this policy.

It is a well-established fact that in diabetic pregnancies the risk of intrauterine death of the foetus is greater in the last four weeks and that this risk increases the nearer the patient is to term. On the other hand, it is also well known that the earlier the foetus is delivered the greater is the risk of death from prematurity. There is therefore no simple answer to this problem of when to deliver the foetus, and the decision must be made for each individual patient after carefully weighing the risk of intrauterine death against the risk of death from prematurity. As there is little risk of death from prematurity once the foetus has reached the thirty-eighth week of gestation, and because of the high risk of intrauterine death after this, there is nothing to be gained by postponing delivery beyond this maturity. However, in some cases it will be necessary to deliver the patient before the thirty-eighth week. The actual maturity at which the delivery should then take place will depend upon the presence of those factors which increase the risks of intrauterine death of the foetus.

The most important of these factors are the severity of the diabetes, whether or not the patient's diabetes is adequately controlled, the previous obstetric history if the patient is a multipara, the presence of pre-eclampsia, the degree of polyhydramnios, the size of the baby, persistently low urinary oestriol output, and, finally, any clinical evidence of placental insufficiency. It is only after careful consideration of all these factors in each individual patient that the correct decision can be made. For example, if the patient is a severe diabetic who is difficult to control and there is pre-eclampsia or increasing polyhydramnios then delivery at 36 or 37 weeks' maturity will have to be considered. Delivery at 35 weeks or earlier is rarely necessary and should not be carried out unless there are very definite indications. The risk of death from prematurity at 35 weeks is at least as high as that of intrauterine death, if not higher.

Table VIII shows that in the present series $42(39.2 \%)$ patients were delivered at 35 weeks or earlier, with the loss of seven babies, a perinatal mortality of $16.7 \%$. Six of these were neonatal deaths due to prematurity, and the seventh was an intrauterine death at 33 weeks which was subsequently delivered at 35 weeks. Delivery at 36 or 37 weeks was carried out in $52(48.6 \%)$ patients with a loss of four babies $(7.4 \%)$. Two of these were intrauterine deaths at 35 weeks, in one of which delivery occurred spontaneously at 36 weeks and the other at 37 weeks. The remaining two were neonatal deaths, one following caesarean section at 36 weeks and one in a patient who had a forceps delivery after induction at 37 weeks; this foetus died 48 hours after delivery, the only positive finding at post-mortem examination being an absent left kidney. The remaining $13(12.2 \%)$ patients were delivered after 37 weeks with a foetal loss of two. In one of these death occurred in utero at the thirty-eighth week in an unsuspected diabetic admitted in an emergency. This patient was confirmed subsequently as having diabetes mellitus, and required insulin therapy. The other loss was the neonatal death of a baby who had multiple abnormalities. The high number of neonatal deaths from prematurity in patients delivered at 35 weeks or earlier illustrates clearly the dangers already mentioned. We believe that our present figures for perinatal mortality can be improved further by selecting the maturity at which delivery should occur according to the factors previously described, and avoiding delivery at 35 weeks or earlier unless very definite indications are present.

\section{Method of Delivery}

Having selected the maturity at which a particular diabetic patient should be delivered the next problem is to decide what is the best method of delivery for that patient. The popularity of caesarean section is revealed by the high caesarean section rates quoted by some authors (Clayton, 1956, 61\% ; Claye and Craig, $1959,58 \%)$. In the present series the caesarean section rate was $66.3 \%$, and of the 33 primigravidae 28 were delivered by caesarean section. This is an increase on the rate quoted by Stevenson (1956) of $55 \%$ (Table VII).

The policy at present most favoured seems to be delivery of primigravidae by elective caesarean section. Those who support this claim do so because the success of present-day methods for medical and/or surgical induction of labour in primigravidae before the thirty-eighth week are disappointing; also, even in those patients whose labour does start there is often a prolonged induction-onset interval with a greatly increased risk of infection, and, should labour be prolonged, control of the diabetes may be difficult. We do not agree entirely with these views, for with the more satisfactory administration of oxytocin by the intravenous or transbuccal routes the success rate for induction of labour has improved. In addition, the mere possibility of a prolonged induction-onset interval or a prolonged labour cannot be considered a valid reason for elective caesarean section, as these complications can easily be prevented. We consider that a medical followed, if necessary, by a surgical induction of labour should be attempted both in primigravidae and in multigravidae, provided there are no contraindications such as disproportion or poor control of the maternal diabetes. If labour has not begun within 12 hours, or if labour has started but is not progressing satisfactorily, then delivery by caesarean section should be carried out.

Management of the Foetus.-It is essential that there should be a good premature-nursing unit with experience in dealing with babies of diabetic mothers; for whether or not the baby survives after delivery will depend to a large extent on expert care by the paediatricians and nursing staff in such a unit. As the vast majority of diabetic babies are born prematurely they must receive the same care and attention that any premature infant requires irrespective of size. For this reason also the prognosis must remain guarded, and in this hospital it is the practice to be quite honest with the patient, telling her that until a week has passed the outlook for the baby is uncertain. This period of waiting imposes immense strain on the diabetic

\begin{tabular}{|c|c|c|c|c|c|c|}
\hline \multirow{2}{*}{$\begin{array}{c}\text { Maturity at } \\
\text { Delivery (Weeks) }\end{array}$} & \multicolumn{2}{|c|}{ Caesarean Section } & \multicolumn{2}{|c|}{ Vaginal Delivery } & \multirow{2}{*}{$\begin{array}{c}\text { Total Viable } \\
\text { Babies }\end{array}$} & \multirow{2}{*}{$\begin{array}{l}\text { Perinatal } \\
\text { Mortality }\end{array}$} \\
\hline & Elective & After A.R.M. & After A.R.M. & Spontaneous & & \\
\hline $\begin{array}{l}30 \\
32 \\
34 \\
35\end{array}$ & $\begin{array}{c}\overline{\overline{\bar{N}}} \\
30(5 \mathrm{NND})\end{array}$ & $\overline{\bar{z}}$ & $\overline{\bar{Z}}_{1(-)}$ & $\begin{array}{l}1(-) \\
1(-) \\
1(\text { IUD) }\end{array}$ & $\left.\begin{array}{r}1 \\
1 \\
73 \\
33\end{array}\right\} 42$ & $\left.\frac{\overline{1}}{6}\right\} 7(16.7 \%)$ \\
\hline $\begin{array}{l}36 \\
37 \\
37+\end{array}$ & $\begin{array}{c}19(1 \text { NND) } \\
7(-) \\
4(1 \text { NND }) \\
\end{array}$ & $\begin{array}{l}2(-) \\
0(-) \\
1(-) \\
\end{array}$ & $\begin{array}{r}8(-) \\
10(1 \text { NND }) \\
4(1 \text { IUD })\end{array}$ & $\begin{array}{l}4 \text { (1 IUD) } \\
2 \text { (1 IUD) } \\
4(-)\end{array}$ & $\left.\begin{array}{l}33 \\
19 \\
13\end{array}\right\} 52(54)^{*}$ & $\left.\begin{array}{l}2 \\
2\end{array}\right\} 4(7 \cdot 4 \%)$ \\
\hline Total & 67 (8 NND) & $4(-)$ & 23 (1 IUD 1 NND) & 13 (3 IUD) & $107(109)^{*}$ & $13(11.9 \%)$ \\
\hline
\end{tabular}


mother ; not only is she denied the immediate joy of seeing and holding her newborn child but she has to face the next few days in doubt and uncertainty, at a time when she should be receiving the reward for months of discipline and weeks of separation from her family. Tact, sympathy, and encouragement are needed at this stage, and the obstetrician should see to it that the patient receives adequate preparation for this final period of waiting in the weeks before delivery.

\section{Summary}

The 113 pregnancies (115 foetuses) occurring in 80 diabetic patients treated in the Royal Maternity Hospital, Belfast, over the eight years 1956 to 1963 have been reviewed.

The total foetal loss was $16.2 \%$ and the perinatal mortality $11.9 \%$. Although these results are an improvement on those of the previous years they are still too high.

The management of these diabetic patients over the past eight years is discussed and those factors considered mainly responsible for the reduction in perinatal mortality are emphasized.

Certain alterations in our present management have been made in the hope that our present foetal loss can be reduced still further. The most important of these are: (1) a special antenatal clinic for diabetic patients attended by both physician and obstetrician ; (2) strict antenatal supervision from the early weeks in an attempt to reduce the number of miscarriages; (3) rigorous control of the diabetes and the use of a twice-daily insulin dosage regime; (4) admission to hospital at least four weeks before the provisional date of delivery and not later than 32 weeks ; (5) the maturity at which delivery should take place must be carefully selected for each individual patient-routine delivery at a particular maturity must be abandoned ; (6) unless there is some contraindication, a trial medical and/or surgical induction of labour with certain reservations should be attempted in primigravid as it is in the multigravid patients.
We wish to thank Professor C. H. G. Macafee and the consultants of the Royal Maternity Hospital, Belfast, for permission to study the obstetric records of these patients. We are indebted to Professor Macafee-who was responsible for the obstetric management of these patients-for his advice and encouragement in writing this paper. The assistance of the tutors and resident medical staff in the management of these patients was invaluable, and to them we are most grateful. We would also like to thank Professor F. M. B. Allen, the consultant paediatricians, and the nursing staff of the premature nursery unit of the Royal Maternity Hospital, without whose skilled care and attention many of the babies might not have survived. Our thanks are also due to Dr. J. A. Weaver and the registrars and senior house officers of the metabolic unit of the Royal Victoria Hospital, who assisted us in the diabetic management of these patients. We also wish to thank Professor E. A. Cheeseman, of the Department of Social and Preventive Medicine, the Queen's University of Belfast, for statistical help; and Miss $M$. Weller for secretarial assistance.

\section{REFERENCES}

Barns, H. H. F., and Morgans, M. E. (1948). F. Obstet. Gynaec. Brit. Emp., 55, 449.

Claye, A. M., and Craig, W. S. (1959). Arch. Dis. Childh., 34, 312.

Clayton, S. G. (1956). F. Obstet. Gynaec. Brit. Emp., 63, 532. Crenshaw, C., Parker, R. T., and Carter, B. (1962). Obstet. and Gynec.,
20, 334.

Dolger, H., Bookman, J. J., and Nechemias, C. (1963). F. Mt Sinat Hosp., 30, 479.

Drury, M. I. (1961). Irish f. med. Sci., 430, 425.

Louw, J. T., and Sinclair, R.St.C. (1957). S. Afr. med. F., 31, 28.

Parkin, G. M. (1958). Med. f. Aust., 1, 622.

Pedersen, J., and Branstrup, E. (1956). Lancet, 1, 607.

Peel, J. H. (1955). Brit. med. F., 2, 870.

- (1962). Amer. 7. Obstet. Gynec., 83, 847.

Stevenson, A. E. M. (1956). Brit. med. f., 2, 1514.

von Schubert, E. (1960). Geburtsh. u. Frauenhèilk., 20, 1029.

White, P. (1949). Amer. f. Med., 7, 609.

(1959). In Treatment of Diabetes Mellitus, edited by E. P. Joslin,
H. F. Root, P. White, and A. Marble, 10th ed. Kimpton, London.

Wilson, R. B., and Morrison, M. G. (1962). Clin. Obstet. Gynec., 5, 419.

\title{
Epilepsy after Ruptured Intracranial Aneurysm
}

\author{
F. CLIFFORD ROSE,* M.B., M.R.C.P. ; MARTIN SARNER, † M.B., M.R.C.P.
}

Brit. med. F., 1965, 1, 18-21

The association of epilepsy with cerebrovascular disease is well recognized, but the frequency with which fits follow a proved ruptured intracranial aneurysm is unknown. In order to ascertain the incidence of epilepsy subsequent to subarachnoid haemorrhage from an intracranial aneurysm a retrospective survey has been done on an unselected group of proved cases and a sample of these personally seen and analysed.

\section{Case Material}

The patients in this series were all those admitted to Atkinson Morley's Hospital during the five-year period 1958-62. Subarachnoid haemorrhage was confirmed in every case by lumbar puncture and the presence of one or more aneurysms proved

- Consultant
Lambeth Hourologist, Royal Eye Medical Ophthalmology Unit, Lambeth Hospital, London ; First Assid

t Research Assistant, Department of Neurosurgery, Atkinson Morley's (St. George's) Hospital, London. by arteriography. Epilepsy is here defined as one or more fits, of any type, occurring at any time after the haemorrhage; there was no case with a history of fits before the bleed. The term "survivor" is applied to those patients who have survived for six months or longer from the time of the bleed.

The series totalled 1,009 cases and there was an excess of females in the proportion of $3: 2$. There were 508 survivors, and of these $53(10.4 \%)$ developed epilepsy (Table I). Since the figure of $10.4 \%$ was derived from case records only, it was decided to examine a sample of the series at a follow-up clinic ; these were the survivors from the 137 cases of ruptured intracranial aneurysm admitted to the neurosurgical unit between 1 July and 31 December 1960 . Of the 63 survivors, 61 attended for the follow-up examination, at which a family and past medical history was again taken, with particular reference to epilepsy. Fits of varying types were found to have occurred in nine cases $(14.8 \%)$. This is four more than expected from the case record survey, which was approximately 10 cases per annum, and indicates that the incidence of epilepsy is prob- 